\title{
Stress Monitoring for Cantilever Construction of Concrete Continuous Bridge with Variable Cross-section
}

\author{
Bin Zhou ${ }^{1, a^{*}}$, Xiang Zhang ${ }^{1, b}$, and Yanguang Xue ${ }^{1, c}$ \\ ${ }^{1}$ State Key Laboratory of Coal Mine Disaster Dynamic and Control, Chongqing University, Chongqing \\ 400044, China \\ a18234086637@163.com, bzx1003946808@gmail.com, ${ }^{c} 20152013052 @$ cqu.edu.cn
}

\begin{abstract}
Keywords: Bridge, Stress Monitoring, Elimination of error, Construction Design
Abstract.Due to the complex topography and strict requirement for the construction as well as the significant effect, from the stress and strain, on the geometric shape of such a continuous bridge with variable cross-section, it is difficult to control the geometric shape of the bridge without stress monitoring. Based on this bridge, this paper introduces the influence of stress on the construction of the concrete continuous bridge. Through the actual monitoring, the conclusions is drew that the changing speed of cantilever elevation is different under the influence of stress and the approximate law of compressive stress (few tensile stress) actually exists in the process of construction. These conclusions contribute to the designs of the bridge conforming to the requirements and accomplish the purpose of monitoring the construction.
\end{abstract}

\section{Introduction}

The construction of the bridge has to go through a long and complex process. In order to ensure the closure precision, shape of bridges and meeting the elevation requirements of the design after a period of operation, it is important to predict the deflection of the superstructure and to be analytical and instruct the behavior at each step of the construction process based on the real-time monitoring data [1].

Stress monitoring of the structure is one of the most important parts in the construction control. For any type of bridge or construction method, stress monitoring must be implemented in the whole construction process. Stress monitoring has to reach the objectives listed below [2-9]:

Monitor the changes and development of the stress in the whole construction process based on the monitoring data, determine whether the structures are under a safe state, whether the structures meet the strength requirements, and whether strength adjustments were needed. If there is any hidden danger,essential measures must be proposed.

Provide monitoring calculation with actual data and valid materials. Check the structure design parameters, the variables of design, validity of the design calculation and the reliability of the construction process and provide a reference for the future bridge monitoring of same type.

\section{Engineering situation}

Due to the complex topography of the region it is in, with rivers needed to be passed to connect the detached areas and after demonstration and decision-making, it is decided to remove the old bridge and construct a new one, meeting the development of the society, at the position of the old one.

The bridge consists of a main span of $135 \mathrm{~m}$ and two sides spans of $85 \mathrm{~m}$ and $88 \mathrm{~m}$. The total bridge length is $308 \mathrm{~m}$ and the width of bridge is $20 \mathrm{~m}$. The configuration of the bridge is a box arch girder, superstructure supported, whose upper-plate has a double-sided cross slope of 1.5\%.The arch girder, whose concrete strength requirements is C55, employs single box multi-room box girders and inclined webs. The height of mid-span-girder is $3 \mathrm{~m}$ and the total height of bottom by nodes is $14 \mathrm{~m}$. The thick of upper plate of box girder is $28 \mathrm{~cm}$, while the bottom plate is $28 \mathrm{~cm}$ in mid-span and $341.3 \mathrm{~cm}$ at root part. 
The bridge consists of a total of 56 cantilever casting segments, each of which extends to the length of $2 \sim 5 \mathrm{~m}$ and weights $180-500 \mathrm{~T}$.

The bridge, which is fixed rigidly on 2 abutments, concreted by T-bridge traveling carriage separately in the sequence of casting of symmetric cantilevers, closure of side spans and closure of mid spans.

\section{Methods of detection}

Choose steel string to the strain gauge and matching frequency receiving apparatus as stress observation instrument. The strain gauge is of stable performance, small temperature error, strong anti-interference, and is suitable for long-term observation to the stress [10]. At present the stress testing has two methods of the direct method and the indirect method [11]. The bridge adopts indirect method, that is, through the conversion getting stress value of the concrete. Generally speaking, stress concrete bridge structure stress is measured continuously in a long time, and the error between the stress value of the whole structure and that of the actual structure is relative large, sometimes even reaching up to about $15 \%$ [12].

According to calculation formula of the steel string wire's tension:

$$
F=4 \rho_{m} l^{2} f^{2}
$$

Type: $\mathrm{F}$ is strings wire's tension; $\rho_{m}$ is the strings linear density; $l$ is the string wire length between the two sites; $f$ is the string silk vibration frequency. We get the stress and strain:

$$
\varepsilon_{a}=\frac{\sigma_{a}}{E_{a}}=\frac{4 \rho l^{2} f^{2}}{E_{a}}
$$

Type: $E_{a}$ is the string wire elastic modulus; $\sigma_{a}$ is the string wire stress; $\varepsilon_{a}$ is the string wire strain. When the strain gauge in distortion, we generally think that quality line is of the same density, only considering string wire length and the change of tension. And we think that the strain gauge and concrete have the same strain increment, namely:

$$
\varepsilon_{\mathrm{w}}=\varepsilon_{a}-\varepsilon_{a 0}=\frac{4 \rho l^{2} f^{2}}{E_{a}}-\varepsilon_{a 0}
$$

Type: $\varepsilon_{W}$ is concrete strain (i.e. string wire strain increment); $\varepsilon_{a 0}$ is string wire initial strain. Then through the concrete elastic modulus can work out the concrete stress:

$$
\sigma_{w}=E_{w} \times \varepsilon_{\mathrm{w}}
$$

By type (3), it can be seen that the strain of concrete $\varepsilon_{W}$ can be seen as the quadratic function of the natural frequencies $f$ :

$$
\varepsilon_{\mathrm{w}}=A f^{2}+B f+C
$$

Type: $\varepsilon_{W}$ is concrete component strain; $f$ is string silk vibration frequency; $\mathrm{A}, \mathrm{B}$ and $\mathrm{C}$ are undetermined coefficient.

By the least square principle, through the data $\left(f, \varepsilon_{w}\right)$ we can determine coefficient $\mathrm{A}, \mathrm{B}, \mathrm{C}$, to obtain quadratic function expression of all the steel string to the strain gauge strain. In stress monitoring, putting the measured steel string frequency values into the quadratic function (5), then we 
work out the concrete structure corresponding strain value, and again by quadratic function (4), we get stress of the structure.

\section{Stress influence}

Bridge pier control section

Each main pier is decorated with two testing section, the section elevation is $186 \mathrm{~m}$ and $206 \mathrm{~m}$ respectively. Each section layout two test points, sensor vertically laid. Specific layout is shown in Figure 1.
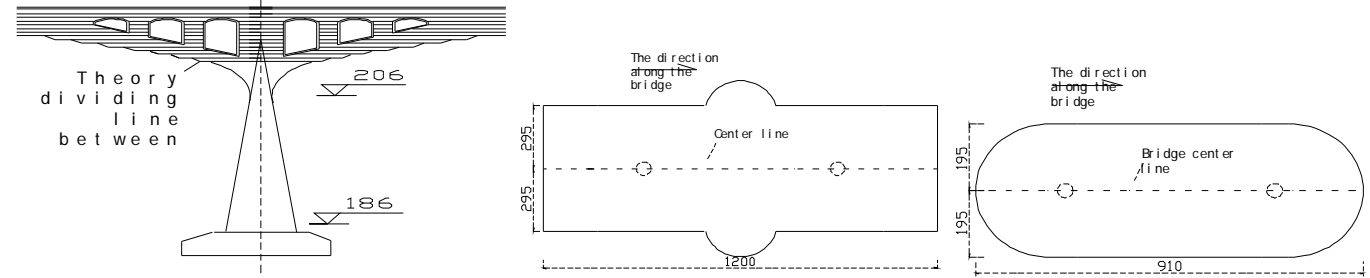

Fig.1 Piers stress point arrangement

The main girder control section

According to the structure characteristics of the bridge, the most important is to measure of the vertical compressive stress of the stress concrete box girder structure, and to master the change of the force. The main girder control section is selected near the No.0 (hang beam root), L / 4, and fold section (L / 2), and so on. $\mathrm{L}$ is the bridge main span (as shown in Figure 2). Because there is some space between the sensors and the top or bottom, the test has some errors, but very small [13], which can be ignored. Section measuring-point arrangement is shown in Figure 3. According to the current general construction monitoring requirement, concrete inner stress test sensor should be ensured that the damage rate of the elements must not be more than 30\% [14]. More than $80 \%$ can be normally tested when the bridge stress sensors in closed.

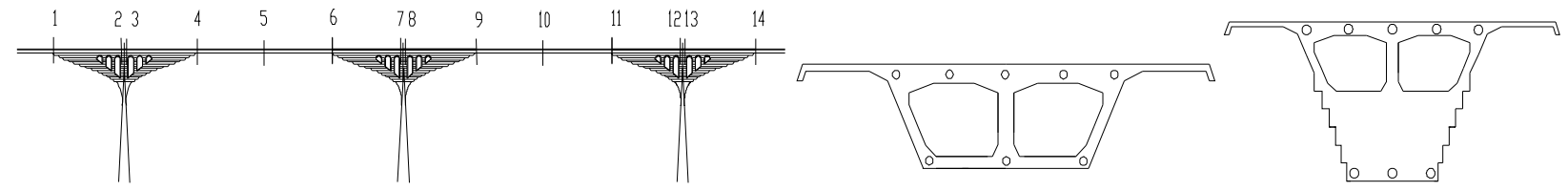

Fig.2 Main stress test section arrangement

Fig.3 Main stress measure point arrangement

In the process of construction supervision, the factors causing stress test error are in the following aspects: installation error of steel string to the strain gauge, concrete elastic modulus error, concrete strain lag error, the temperature error, the creep error and shrinkage of the concrete.

The actual stress of the monitoring station is these errors measuring stress read deducting the initial strain, error of the creep and shrinkage error, the temperature error. Namely:

$$
\sigma=\sigma_{e d}-\sigma_{e c}-\sigma_{x b}-\sigma_{s s}-\sigma_{w d}
$$

Type: $\sigma$ is the actual stress of the measuring station; $\sigma_{e d}$ is sensor readings stress; $\sigma_{e c}$ is the initial stress value of the sensor; $\sigma_{x b}$ is the concrete creep stress error of the measuring station; $\sigma_{s s}$ is the concrete shrinkage stress error of the measuring station; $\sigma_{w d}$ is the stress error caused by temperature.

The main piers stress monitoring results in the following Table 1. 
Table 1 P1 pier 186 section test results

\begin{tabular}{|c|c|c|c|c|c|c|}
\hline \multirow{2}{*}{ Construction stage } & \multicolumn{3}{|c|}{ P1 pier 186 small pile side, cross section } & \multicolumn{3}{|c|}{ P1 pier 186 big cross section, pile side } \\
\hline & theoretical & measured & error & theoretical & measured & error \\
\hline Piers complete & -0.24 & -0.01 & -0.33 & -0.24 & -0.13 & -0.20 \\
\hline O\#lump complete & -2.11 & -2.35 & 0.14 & -2.11 & -1.13 & -1.07 \\
\hline 1-2\#lump complete & -2.87 & -2.73 & -0.14 & -2.87 & -2.64 & -0.32 \\
\hline 3\#lump complete & -3.16 & -3.18 & -0.07 & -3.16 & -3.47 & 0.21 \\
\hline 4\#lump complete & -3.44 & -3.63 & 0.09 & -3.44 & -3.65 & 0.11 \\
\hline 5\#lump complete & -3.69 & -3.85 & 0.06 & -3.69 & -3.89 & 0.10 \\
\hline 6\#lump complete & -3.91 & -3.97 & -0.03 & -3.91 & -4.17 & 0.16 \\
\hline 7\#llump complete & -4.12 & -4.04 & -0.17 & -4.12 & -4.23 & 0.01 \\
\hline 8\#lump complete & -4.33 & -4.51 & 0.08 & -4.44 & -4.74 & 0.20 \\
\hline 9\#lump complete & -4.47 & -4.73 & 0.16 & -4.58 & -4.85 & 0.17 \\
\hline 10\#lump complete & -4.67 & -4.76 & -0.07 & -4.77 & -4.76 & -0.11 \\
\hline 11\#lump complete & -4.85 & -5.12 & 0.17 & -4.94 & -4.98 & -0.05 \\
\hline 12\#lump complete & -5.03 & -5.33 & 0.20 & -5.11 & -5.19 & -0.01 \\
\hline 13\#lump complete & -5.20 & -5.25 & -0.04 & -5.00 & -4.97 & -0.12 \\
\hline 14\#lump complete & -5.36 & -5.57 & 0.11 & -5.16 & -5.03 & -0.22 \\
\hline Edge folded across & -5.56 & -5.45 & 0.08 & -4.51 & -4.79 & 0.18 \\
\hline Across fold in & -5.57 & -5.49 & 0.12 & -3.95 & -4.12 & 0.07 \\
\hline Second stage & -5.91 & -5.87 & -0.03 & -4.52 & -4.56 & -0.05 \\
\hline
\end{tabular}

As the monitoring data reveals, the stress of the main piers is generally small, the control section is under compressive stress, rare tensile stress appearing in construction process, and the measured maximum compressive stress is $5.87 \mathrm{MPa}$, appeared in small side of the 186 cross-section P1 pier. All do not exceed the maximum theory compressive stress, 5.91 MPa of the control stress. The measured stress value goes with the theory stress value consistently. The variation trend of the theory stress is basically in correspondence with that of the measured one. The maximum error is $1.07 \mathrm{MPa}$, and the measured maximum is far less than the standard axis compressive strength, $26.8 \mathrm{MPa}$, of the concrete C40.

The results of the measured stress of the main girder are list in Table 2 . In the table, the tensile stress is positive and the compressive stress is negative. 
Table 2 Section roof test results

\begin{tabular}{|c|c|c|c|c|c|c|}
\hline \multicolumn{7}{|c|}{3 section roof test results } \\
\hline \multirow{2}{*}{ Construction stage } & \multicolumn{3}{|c|}{ upstream } & \multicolumn{3}{|c|}{ downstream } \\
\hline & theoretical & measured & error & theoretical & measured & error \\
\hline 1-2\#lump pouring & -1.08 & -0.99 & -0.18 & -1.08 & -1.63 & 0.45 \\
\hline 3\#lump pouring & -2.11 & -1.96 & -0.24 & -2.11 & -2.57 & 0.36 \\
\hline 4\#lump pouring & -3.1 & -2.88 & -0.3 & -3.1 & -3.08 & -0.11 \\
\hline 5\#lump pouring & -3.95 & -4.23 & 0.18 & -3.95 & -3.37 & -0.67 \\
\hline 6\#lump pouring & -4.74 & -4.63 & -0.20 & -4.74 & -3.96 & -0.88 \\
\hline 7\#lump pouring & -5.44 & -5.48 & -0.05 & -5.44 & -4.43 & -1.10 \\
\hline 8\#lump pouring & -5.94 & -5.85 & -0.18 & -5.94 & -5.47 & -0.56 \\
\hline 9\#lump pouring & -7.03 & -7.56 & 0.43 & -7.03 & -7.55 & 0.42 \\
\hline 10\#lump pouring & -7.81 & -7.94 & 0.03 & -7.81 & -8.64 & 0.73 \\
\hline 11\#lump pouring & -8.36 & -8.38 & -0.08 & -8.36 & -9.12 & 0.66 \\
\hline 12\#lump pouring & -8.83 & -9.07 & 0.14 & -8.83 & -9.09 & 0.16 \\
\hline 13\#lump pouring & -9.29 & -9.58 & 0.19 & -9.29 & $\begin{array}{l}-9.61 \\
\end{array}$ & 0.22 \\
\hline 14\#lump pouring & -11.61 & -10.33 & -1.37 & -11.61 & -10.19 & -1.51 \\
\hline $\begin{array}{r}\text { Across the } \\
\text { counterweight }\end{array}$ & -12.18 & -11.66 & -0.61 & -12.18 & -11.46 & -0.81 \\
\hline Edge folded across & -10.3 & -10.58 & 0.18 & -10.3 & -9.70 & -0.69 \\
\hline Off Shelf & -10.61 & -10.93 & 0.22 & -10.61 & -10.03 & -0.67 \\
\hline Across the balance in & -10.56 & -10.62 & 0.16 & -10.36 & -9.72 & -0.73 \\
\hline Across fold in & -11.2 & -10.83 & -0.46 & -11.2 & -10.58 & -0.72 \\
\hline Second stage & -11.1 & -9.98 & -1.21 & -11.1 & -9.78 & -1.41 \\
\hline
\end{tabular}

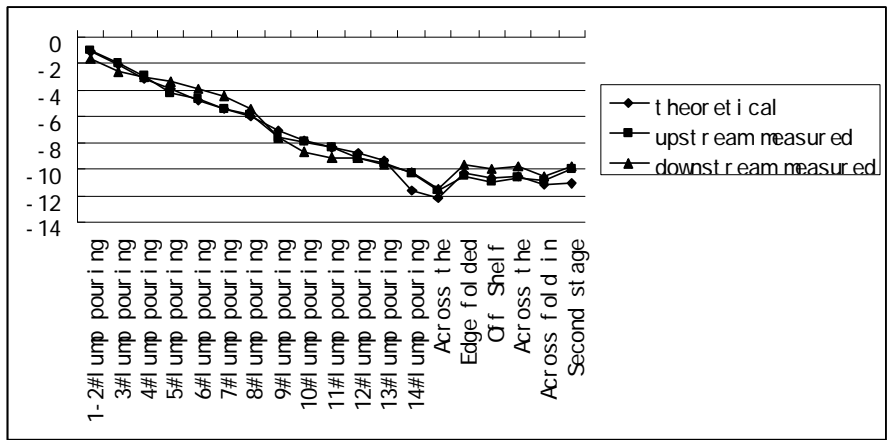

Fig.4 The curve of the measured stress and the theory stress of the roof

It is indicated in the graph above that the variation trend of the theory stress is in correspondence with that of the measured one. Due to the influence of various complicated factors, the measured strains would reveal that the model does not take everything into consideration in the strain test and it is natural that the measured value is not identical to the theory value. The measured stress and the theory stress of the bridge is considerably consistent in the construction process .Individual large error is caused by the concrete elastic modulus error and the influence of the uneven hydration heat in the box girder when the concrete is still of short time. The maximum error of the whole bridge is 1.07 
MPa. During the construction process, the main stress mainly comes from compressive stress, hardly from tensile stress. The maximum compressive stress is $11.61 \mathrm{MPa}$ which is far less than the allowable stress of $35.5 \mathrm{MPa}$ of the C55 concrete. And this shows the safety of the structure.

\section{The conclusion and prospect}

The monitoring of the stress of the variable cross section continuous beam bridge cantilever not only ensures the safety of the bridge construction but also plays a role of reference for the future similar projects. Based on the monitoring results, I get the following conclusions:

(1) Stress test error, mainly including sensor installation error, error of the elastic modulus of concrete, concrete strain hysteresis error and temperature effect errors and shrinkage and creep errors. In order to obtain relatively accurate stress values, the strain caused by the shrinkage and creep of the concrete, and by the difference of the temperature should be separated and wiped out.

(2) From the monitoring results, the difference between the theory stress of the main beam and the measured stress is small, which shows the correctness of the structure calculations and that the selected material parameters correspond to the actual situation, that the steel wire strain gauges for long-term concrete strain monitoring is successful, and that its accuracy can meet the requirements of the monitoring work.

(3)The stress on the beam is virtually the compressive stress rather than the tensile stress.

Because of the limited capacity, the study has some inadequacies. At present, most of the layout program of the bridge sensor is empirical, the main direction of our research is to use the least sensors to obtain complete and accurate information on the structural parameters, and this is also position needed to be improved in the future monitoring.

\section{References}

[1] Lijia Song. Cantilever construction of a continuous bridge linear control technology[J]. Sichuan Architecture. Vol.28(2)(2008):184-187.

[2] NorioTerada, Toshiaki Moshiaki.theDesign and Construetion of the Niyakodagawa Bridge in the 2nd Tomei Expressway; Proeeedings of the 1st FBI Congess, Session2:71-80, Japan.

[3] Sakai F,Isoe A,Umeda A.A new methodology for control of construction accuracy in cable- stayed bridges[A].Fan L C.Proc 3th EASEC. Shanghai:Tongji University Press, 1991:847 855.

[4] Jacques Mathivat. The Cantilever Construction of Prestressed Conerete Bridges.John Wiley\&Sons, 1983.

[5] Wada K,Tomita N,Takano H.Construction of theYokohama Bay Bridge superstrueture [A].Zurich:IABSE,1988:177 182.

[6] Kalman R E. A new Approach to Linear Filtering and Prediction Problems.ASME,Journal of Basic Engineering, 1960:82.

[7] Doebling S W,Farrar C R. Computation of Srructural flexility for bridge health monitoring using ambient modal dama[Al.In:Proc.of 11st ASCE Engineering Mechanics Conference[C]. Ft.Lauderdale, and USA:1996: 1114 1117.

[8] Richard Malm, and Hakan Sundquist. Time-dependent analyses of segmentally constructed balanced cantilever bridges[J]. Engineering Structures. Vol.32(4)(2010):1038-1045. 
[9] John Leander , Andreas Andersson and Raid Karoumi. Monitoring and enhanced fatigue evaluation of a steel railway bridge[J]. Engineering Structures. Vol.32(3)(2010):854-863.

[10]H.Yoshioka, Ramallo JC, Spencer Jr. B.F. Base Isolation Strategies Employing Magnet or heological Dampers[J]. Journal of BridgeEngineering Mechanics, MAY 2002: 880 885.

[11]Hui Wang. Stress Monitoring of Prestressed Concrete Cast-in-situ Continuous Beam of Bajianghe Bridge[J]. Hunan Communication Science and Technology. Vol.35(3)(2009):117-120.

[12]Musheng Xiang. Process Control Technology During Cast-in-place Cantilever Construction in Long Span Prestressed Concrete Continuous Beam Bridge[J]. Journal of Highway and Transportation Research and Development. Vol.21(1)(2004):71-73

[13]Musheng Xiang. Stress Test Technique to Prestressed Concrete Beam Bridge[J]. Journal of Wuhan University of Technology(Transportation Science \& Engineering). Vol.25(3)(2001):266-269

[14]Linyan Fan. Baoshu Highway Yellow River Bridge construction monitoring data analysis[J]. Highway. vol.1(12)(2010):32-35 